\title{
REFORMAS DEL ARTE DE NEBRIJA EN LA SEGUNDA MITAD DEL SIGLO XVI. EL CASO DE MARTÍN SEGURA DE ALCALÁ
}

\author{
Eustaquio Sánchez Salor \\ Universidad de Extremadura \\ esanchez@unex.es
}

\begin{abstract}
RESUMEN
En la segunda mitad del siglo XVI aparecen una buena cantidad de Institutiones de Gramática, las cuales, frente a las Introductiones de Nebrija, que era la Gramática oficial y que se había convertido en un manual largo y difícil para los alumnos, trataban de imponerse apareciendo como una Gramática más breve y racional que la de Antonio. Así las Institutiones de Segura en Alcalá, editada por primera vez en 1580 y reeditada en 1586 y 1589. La edición de 1580 se presenta como breve y racional, pero también como instrumento para enseñar a hablar latín, para lo cual incorpora al texto gramatical muchas frases latinas. Debió recibir críticas Segura por ello. En la reedición de 1589, entre otros cambios, suprime una buena cantidad de las frases latinas. Cede algo ante la presión de los gramáticos racionalistas que sostenían que no se debía hablar latín.

Palabras ClaVE: Reforma Gramática Nebrija, Martín de Segura, Universidad Alcalá, Institutiones de Gramática.
\end{abstract}

\section{REFORMS OF THE ART OF NEBRIJA IN THE SECOND HALF OF THE 16TH CENTURY. THE CASE OF MARTÍN SEGURA DE ALCALÁ}

\section{ABSTRACT}

In the second half of the $16^{\text {th }}$ century, a good number of Institutions for the Grammar appeared. Compared to the Introducciones de Nebrija, which was the official Grammar and which had become a long and difficult manual for students, the aforementioned Institutions for the Grammar tried to present themselves as a shorter and more rational Grammar than Antonio's. This is the case of the Institutions of Segura in Alcalá, first published in 1580 and reprinted in 1586 and 1589 . The edition of 1580 is presented as brief and rational, but also as an instrument to teach Latin language, for which it incorporates many Latin phrases into the grammatical text. Segura must have been indeed criticized for it. In the 1589 reprint, among other changes, it suppresses a good number of Latin phrases. He gave in somewhat to the pressure of rationalist Grammarians who argued that Latin should not be spoken.

KeYWORDS: Nebrija Grammar Reform, Martín de Segura, Alcalá University, Grammar Institutions. 
El Arte de Gramática de Nebrija conoció a lo largo de todo el siglo XVI numerosas reediciones. En la mayoría de los casos eran reediciones aumentadas con comentarios y opúsculos, de manera que terminó por convertirse en todo lo contrario a un manual más o menos útil para los alumnos (Sánchez Salor, 2008). Por ello pronto empezaron las protestas y los intentos de componer gramáticas, con el mismo esquema que la de Nebrija, pero despojadas de todo el contenido superfluo. He dicho que con el mismo esquema, lo cual quiere decir lo siguiente: la obra de Nebrija tenía cinco libros; en el primero se recogían las declinaciones y conjugaciones; en el segundo se daban en verso las reglas del género del nombre y de los pretéritos del verbo; en el tercero se explicaban, mediante el sistema de preguntas y respuestas, las partes de la oración; el cuarto era el de la Sintaxis o Construcción; y el quinto, el de la Prosodia y Métrica. Pues bien, los Gramáticos que pretenden mejorar la obra de Nebrija se mantienen en ese esquema de cinco partes, con el mismo contenido cada una de ellas. Pero mucho más breves y con algunos cambios. Y es que era difícil suplantar radicalmente la obra del maestro; no terminó siendo tan difícil mejorarla o presentarla como mejorada. Es lo que termina sucediendo con la conocida reforma del padre Juan Luis de la Cerda en 1601.

Pero no es la de Juan Luis de la Cerda la única reforma del Arte de Nebrija, a pesar de que siempre se ha hablado sólo de ella. Ya en 1599 hubo otra, que hemos analizado en otro lugar (Sánchez Salor, 1999). Y, más atrás en el tiempo, encontramos otras reformas, en las que, con el mismo esquema de Nebrija, se abreviaba y se pretendía mejorar el contenido de Antonio. Tal es el caso nada menos que el de la Institutiones del Brocense de $1562^{1}$ y de la Gramática de Martín de Segura de Alcalá de 1580, reeditada en 1589. La obra de Segura nace aprovechando las discusiones y pleitos entre los herederos de Nebrija, que defendían que se debía seguir enseñando por la Gramática de su antecesor, y los jesuitas, que pretendían ya que se enseñara por sus Gramáticas; entre ellas, la del padre Alvarez; es lo que se desprende al menos de lo que se dice en el Privilegio o Licencia de la segunda edición de 1586, según recoge Hernández Miguel:

Vos auiades hecho vn arte de grammatica, aura seys años, y auiendo pleyto en aquella sazon entre los padres de la compañia y los herederos de Antonio de Nebrixa, os auiamos hecho merced de daros licencia para imprimirla

La compañía era naturalmente la de Jesús y el pleito, una acusación de plagio que los herederos de Nebrija habían hecho a la Gramática del padre Álvarez, quien había publicado en 1572 en Lisboa su De institutione grammatica libri tres. La Gramática de Martín Segura nace, pues, aprovechando el resquicio que dejan las discusiones sobre qué Gramática se debe enseñar: si la de Nebrija o las que compongan los nuevos maestros de las Universidades (Hernández Miguel: 338).

${ }^{1}$ http://bdh-rd.bne.es/viewer.vm?id=0000240776\&page=1. 
En medio de esas discusiones nació también la Minerva del Brocense en Salamanca. En el caso de Segura se ve en algún momento el intento de meterse entre el padre Álvarez y Nebrija.

Llama la atención el hecho de que tanto el Brocense, como Martín de Segura justifiquen el carácter de reforma de su obra diciendo que Antonio fue un gran maestro, que fue el debelador de la barbarie en España, que los españoles deben estarle muy agradecidos, pero que, como en todo maestro, también en él hay cosas que pueden ser mejoradas; y que incluso, si Antonio viviera en la segunda mitad del siglo XVI, sería él mismo el que introduciría reformas.

El Brocense lo dice en la Minerva de 1584, en un pasaje que ha sido bien interpretado por el profesor Maestre Maestre (1899 y 1988-90). Pero lo que dice en la Minerva de 1584 lo había dicho veintidós años antes en el Prefacio de la edición de Lyon, 1562, de las Institutiones, que es donde realmente tiene verdadero sentido la apariencia de que se intenta mejorar al maestro Antonio; la Minerva no es una mejora de la Gramática de Nebrija, sino una ruptura total. En las Institutiones de $1562^{2}$ comienza Sanctius alardeando de que él se aparta de otros Gramáticos, y que quizá ello moleste a muchos: tibi fortasse videor rem flagitio dignam incepisse, quod a Veterum vestigiis Grammaticorum longe discedam ("quizás a ti te parezca que emprendo una acción digna de castigo, porque me aparto mucho de las huellas de los antiguos gramáticos»). En esta edición de las Institutiones añade al final una primera versión breve de la Minerva $a^{3}$ y en el primer capítulo de la misma dice algo similar: Quoniam res de qua agimus primum ratione deinde testimoniis est comprobanda, nemo mirari debet si magnos interdum uiros non sequamur («Puesto que el tema del que tratamos debe demostrarse primero con la razón y luego con testimonios, no debe extrañar a nadie que de vez en cuando yo no siga a los grandes maestros»). Y es que, volviendo al prólogo de la Institutiones, nadie inventa nada perfecto: Imo vero tecum reputa nibil simul inventum et perfectum ( (Recapacita, más bien, que nada que se invente es ya perfecto en el momento de la invención»). Por ejemplo, sigue diciendo, mucho debe España a Nebrija, ya que recuperó las letras que estaban muertas y expulsó de nuestras tierras la barbarie: Multum debet Hispania Antonio Nebrissensi; ille morientes litteras apud nos suscitavit; ille barbariem feliciter ex nostris terminis expellere tentavit («Mucho debe España a Antonio de Nebrija; él hizo que las moribundas letras resucitaran entre nosotros; él intentó felizmente echar de nuestras fronteras la barbarie») $)^{4}$. Pero la obra de Antonio es perfeccionable y el mismo Antonio, si viviera todavía en época de Sanctius, dice éste ya en 1562, corregiría muchas cosas; y recurre a una cita de Horacio en la que éste decía lo mismo de su antecesor satírico Lucilio. Horacio ${ }^{5}$ decía de Lucilio

${ }^{2}$ http://bdh-rd.bne.es/viewer.vm?id=0000240776\&page=1.

${ }^{3}$ Esta pequeña Minerva fue editada por E. del Estal Fuentes, Francisco Sánchez de las Brozas. Minerva (1562), Salamanca: Universidad de Salamanca, 1975.

${ }^{4}$ fol. Aiii.

${ }^{5}$ Hor., Sat. 1.10.64ss. 
que era comis et urbanus, limatior, Graecis intacti carminis auctor qamque poetarum seniorum turba («ameno y exquisito, muy perfeccionista, autor de versos no compuestos por griegos o por poetas antiguos»), pero el mismo Lucilio, si foret hoc nostrum fato dilatus in aevum, I detereret sibi multa; recideret omne quod ultra I perfectum traheretur ${ }^{6}$ («si los hados le hubieran dejado vivir hasta nuestros días, corregiría muchas cosas suyas y cortaría todo lo que no fuera perfecto»). Lo mismo que dice Horacio de Lucilio dice también Sanctius de Nebrija; la obra de éste, extraordinaria, necesita reforma. Para esa reforma, él, Sanctius, en su época, cuenta ya con doctrina sabia de otros gramáticos que, junto con la del propio Nebrija (ipsius et aliorum adjuti laboribus) le permiten reformar y mejorar más fácilmente el Arte de Antonio: Nos vero ipsius et aliorum adjuti laboribus, plura, idque facilius, consequi possumus («Yo, por mi parte, con la ayuda de trabajos del propio Nebrija y de otros, alcanzaré objetivos mayores, y ello con más facilidad»).

Pues bien, Martín de Segura de Alcalá, en su Grammatica Institutio de 1580, utiliza exactamente el mismo argumento que Sanctius para justificar su reforma de las Introductiones de Nebrija con una Institutio ${ }^{8}$. También lo de Sanctius eran unas Institutiones, además verae y breues, frente a las Introductiones de Nebrija. Segura, dirigiéndose al lector, dice que se siente como un continuador del Lebrijano. Pero también es cierto que con intención de reformar. En el juicio que por mandato del Consejo Real hace de la obra Matthaeus Othenus, éste observa, en efecto, ya la existencia en ella de aspectos que discrepan de Nebrija, pero que se presentan probabili ratione («con razonada verosimilitud»). Y es que el autor, como dice dirigiéndose al lector, se siente como un continuador del Lebrijano que, precisa Martin de Segura, si se lo hubiese permitido la vida, habría corregido su obra añadiendo, quitando y cambiando cosas. Esto lo dice en la advertencia lectori de $1580^{\circ}$. Comienza reconociendo los méritos de Antonio (fol 9r): Antonius Nebrissensis (cui ego siquid literis possum acceptum refero) fuit sane decus eruditorum et Hispaniae ornamentum insigne, qui primus expulsa barbarie latinas literas in Hispaniam introduxit ("Antonio Nebrisense, al que concedo respeto si es que tengo alguna autoridad en letras, fue sin duda un destacado sabio y honra insigne de España, ya que fue el primero en introducir las letras

${ }^{6}$ fol. iiii. La Minerva, hemos dicho, no es una reforma de las Introductiones de Nebrija, sino una ruptura total. Por eso, en la Minerva cambia la cita clásica en la que apoya Sanctius su afirmación de que Nebrija es perfeccionable. En las Institutiones la cita era de Lucrecio y, como vemos, su contenido es suave. En la Minerva es una cita de contenido vengador. Es aquella en la que Dido anuncia que quizás de sus restos surja algún día un vengador: exoriare aliquis nostris ex ossibus ultor (Aen. 4, 625). Esta cita presenta a un Brocense, no reformador, sino vengador de algo que está mal hecho.

${ }^{7}$ fol. Aiiii.

${ }^{8}$ Curiosamente, todas estas reformas reciben por parte de sus autores el nombre de Institutio o Institutiones frente a la obra de Nebrija que eran Introductiones.

${ }^{9}$ https://babel.hathitrust.org/cgi/pt?id=ucm.5325300568\&view=1 up\&seq=31. 
latinas en España, tras expulsar la barbarie» ${ }^{10}$. Pero añade que, si Antonio hubiera vivido más, él mismo habría corregido cosas de su obra: tamen si illi vita diutius suppeditasset, adictis, detractis, aut permutatis quibusdam suum elaboratum opus fortasse corrigeret («sin embargo, si hubiera vivido más, quizás hubiera corregido su elaborado trabajo añadiendo, quitando o cambiando algunas cosas»). Y vuelven los halagos: Ea erat illius prudentia et huius artis varietas et multiplex rerum usus («tal era su prudencia, la flexibilidad de su arte y los múltiples recursos que tenía») ${ }^{11}$. Él se atreve a recoger

${ }^{10}$ En la edición de 1589 (https://babel.hathitrust.org/cgi/pt?id=ucm.5326814403\&view= 1 up\&seq=28), los elogios a Nebrija son expresados con estas palabras: cum multi viri docti, editis artibus Grammaticae, hactenus ad ingenia puerorum iuuanda, studium accurate contulerint, praecipue Antonius Nebrissensis, literatorum splendor, qui primus ex Hispaniae finibus barbariam eiecit, alicui fortase videbitur superuacaneum nos in eandem curam nouissime incumbere (fol 6v) ("Cuando los doctos gramáticos analicen con detenimiento las Artes de Gramática hasta ahora editadas, que eran una ayuda para los estudiantes, sobre todo la de Antonio de Nebrija, esplendor de las letras, que fue el primero que expulsó la barbarie de los límites de España, pensarán algunos de ellos que es inútil que yo vuelva de nuevo a ocuparme de lo mismo»). No sólo habla de Nebrija, sino de otros muchos viri docti y además aparece un detalle reivindicativo que no estaba en 1580: le han criticado el contenido de sus Institutiones de 1580, y aquí trata de reivindicar su posición; aunque, como veremos en este trabajo, modifica muchas cosas, arrastrado quizás por esas críticas.

${ }^{11}$ En 1589 esos halagos a Nebrija son de esta forma: Sed cum idem summus vir, si diutius vita suppeditasset, suum elaboratum opus corrigeret et in scola hac tritum sit et peruagatum breuiori tempore, domi nostrae, pueros Grammaticis praeceptionibus et elegantia Latinae linguae informari, quam alibi nuda praecepta didicisse, non defuerunt sapientissimi viri qui nos ad tradenda breniter et expedite praecepta illustrium exemplorum usu locupletata crebris sermonibus incitauerint («Pero como este mismo extraordinario varón, si hubiera vivido más tiempo, habría corregido su elaborada obra, y como en esta Academia, en nuestra casa, es muy sabido y está muy extendida la idea de que es necesario enseñar a los muchachos la lengua latina en breve tiempo mediante reglas gramaticales y usos elegantes de la misma, en lugar de sólo con secas reglas como se hace en otros lugares, no han faltado hombres sabios que nos han animado a transmitir con brevedad y claridad los preceptos gramaticales enriquecidos con usos de ejemplos ilustres y con frecuentes ejercicios de composición»). De nuevo aparece el tono reivindicativo que no estaba en 1580: es sabido, dice, que in hac schola (Alcalá) se piensa que hay que enseñar a los niños preceptos y elegancias (modos loquendi), no como en otras en las que sólo se enseñan nuda praecepta. El tono reivindicativo continúa con las siguientes palabras de 1589: Qui si hisce annis primum editus a nobis et oppugnatus a quibusdam vehementer et callide magnum studiosis adiumentum attulit, quid censes, amice lector, postea futurum, cum nunc limatior et ad teneras puerorum mentes accommodatior exeat? Et maleuolorum deferbuerit iracundia, publicis commodis confutata? Quam ob rem si qui sunt qui hisce vigiliis obtrectent et alias extollant, composito et meditato verborum pondere meminerint id a viris bonis alienissimum esse et animacula parua magnis belluis negotium aliquando facessere, fierique posse ut multiplici damno lacessiti erumpentibus aculeis, qui nunc reconditi sunt, id acriter meritoque vindicemus. Vale (Si en estos años, la primera edición de esta obra ha sido criticada con vehemencia por algunos y ha servido también sabiamente de ayuda a los estudiantes, ¿qué piensas, amigo lector, que pasará ahora que sale de nuevo más perfeccionada y más apropiada para las tiernas mentes de los niños? ¿Volverá a hervir la ira de los enemigos, que ha sido refutada por el propio beneficio público? Por ello, si hay algunos que critiquen a esta Gramática que es el resultado de mis desvelos y ensalcen a otras, que piensen concienzudamente que eso no es propio de gente buena y que individuos insignificantes han dirimido a veces sus asuntillos en duras guerras, y que puede ocurrir que yo me vengue con dureza y con razón haciéndoles mucho daño con picotazos que puedo dar y que ahora tengo guardados). 
los preceptos gramaticales (has praeceptiones institui colligere) en esta obra por varias razones: en primer lugar, por consejo de su maestro Trujillo: admonitus ab insigne doctore Trugillio, magistro meo, legionensique episcopo vigilantissimo, qui non solum diuina mysteria, sed has etiam artes accutissime expendit («aconsejado por el insigne doctor Trujillo, maestro mío y obispo muy activo de León, que trabajó no sólo sobre los misterios divinos, sino también sobre artes como esta»). En segundo lugar, porque en algunas cosas, con el permiso de Antonio, discrepa de la opinión de éste: quod de nonnullis (pace antonii sapientissimi viri) aliter sentiam; en concreto no está de acuerdo en utilizar el verso, como hacía Antonio en el libro segundo, porque los alumnos entienden mejor la prosa que el verso: puerque faciliius oratione soluta, quam carmine eas intelligat. En tercer lugar, porque él va añadir en su obra algo que no estaba en Nebrija: copia elegantium modorum, es decir, un arsenal de giros latinos elegantes.

Es, pues un continuador de Nebrija, pero reformándolo. De hecho, presenta su Grammatica Institutio como una reforma del Arte de Nebrija.

Y es que los esfuerzos de los Gramáticos de la segunda mitad del siglo XVI por introducir su doctrina en un ambiente en el que la que se imponía era el Arte de Antonio encontraron solución por una doble vía. A mediados del XVI el procedimiento para dar a luz la propia doctrina frente a la de Antonio fue primero el de hacer comentarios a la Gramática de Antonio (Sánchez Salor, 2005). Concretamente al libro IV, que es el de la Sintaxis, y, menos, al libro V. A partir de los años 70 podemos hablar de una nueva etapa a este respecto. Terminan los comentarios a los libros IV y V de Nebrija y se atisba un intento de volver a editar Gramáticas enteras, que, en teoría, deberían sustituir o reformar al Antonio, intento que en Salamanca llevaron a cabo con gran empeño los maestros Martínez (Sánchez Salor, 2006) y Sánchez de las Brozas. No es nada más que un paso más: se empezaba por comentar a Nebrija y se termina por hacer Gramáticas propias (Sánchez Salor, 2002). En Alcalá tenemos noticias (Hernández Miguel, 1996) de que en 1574 el dominico Pedro Aguirre publicó unas Institutiones grammatices y Martín Jimeno unas Institutiones grammatices linguae latinae, pero hoy se hallan sin localizar y no podemos aventurar su contenido y menos su posición concreta.

Sin embargo, sí conservamos ejemplares de la Grammatica institutio de Martín Segura y de la Gramática de Pedro Simón Abril. Vamos a analizar el sentido de la reforma propuesta por Segura.

La obra, dice Hernández Miguel, tuvo bastante éxito y se empleó en «muchas universidades y estudios particulares, donde se avia hecho y hazia grande fructo con el», si bien fue también fuertemente atacada por algunos. Por todo ello, en 1586 se autoriza una nueva edición corregida, más acomodada ad teneras puerorum mentes (así se recoge en la licencia de la edición de 1586 y en las palabras al lector) en la que se hacen retoques aquí y allí. Una prueba de la continuación de su éxito, a pesar de sus detractores, es que nos consta que fue la gramática con la que se enseñó latín al futuro Felipe III' ${ }^{12}$.

${ }^{12}$ Así consta en la carta dirigida a Martín Segura por el licenciado Juan García y que precede a la Expositio Rerum gestarum in concertatione grammatica Philippi III recogida por este último y hecha publicar por el mismo en Alcalá en 1588, año en que tuvieron lugar los hechos recogidos. 
Una nueva edición, que no parece diferir mucho de la anterior, se publica en 1589. Esta última, como ya hemos apuntado en detalles del prólogo, tiene claro carácter reivindicativo; el ad lectorem de 1589 es, en efecto, reivindicativo, frente al carácter programático de ese mismo ad lectorem en 1580. La primera edición debió ser criticada, sobre todo porque recogía muchos modos loquendi latinos. Textos que demuestran el carácter reivindicativo de 1589 hemos recogido ya en notas anteriores. Seguiremos viendo a lo largo de ese trabajo los cambios que se producen entre una edición y otra, que afectan sobre todo a la supresión de modos loquendi latinos; ello indica que las críticas habrían ido por ese camino.

Vamos a orientar el trabajo a analizar las coincidencias y diferencias que hay entre las Introductiones de Nebrija y la Grammatica Institutio de Segura; e incluso entre la edición de 1580 y la de 1589 del propio Segura. Y es que, si estamos ante una reforma, como anuncia el propio autor y como hemos visto hasta ahora, tiene que haber algo del Arte anterior y algo de nuevo. De lo contrario no se trataría de una reforma, sino de una demolición.

\section{MANTENIMIENTO DEL ESQUEMA DE NEBRIJA}

De la importancia en su época de esta Gramática de Segura es una prueba el hecho de que de ella se nos han conservado ejemplares de todas sus ediciones (Hernández Miguel, 1996: 335-336). Hemos analizado la primera edición de 1580 y la de 1589. La de 1580 es:

Martini Segurae Matutensis in Complutensi gymnasio professoris eloquentiae Grammatica instittutio in quatuor libros tributa, Compluti $1580^{13}$.

La de 1589:

Martini Segurae Matutensis in Complutensi gymnasio professoris primarii, eloquentiae Grammatica instittutio in quatuor libros tributa, Compluti $1589^{14}$.

Sin duda esta obra viene a encarnar la postura de los que consideraban que había que romper de una vez la permanencia pétrea de Nebrija; ello en Alcalá. Es la misma postura que la de los ya citados Martínez y Sánchez en Salamanca; y que la de Palmireno y Sempere ${ }^{15}$ en Valencia. De hecho ya hemos visto que Segura y Sánchez ponen la misma excusa para justificar la reforma: si Nebrija viviera, él mismo firmaría la reforma. Palmireno en Valencia no es tan elegante con Nebrija.

${ }^{13}$ https://babel.hathitrust.org/cgi/pt?id=ucm.5325300568\&view=1 up\&seq=31.

${ }_{14}^{14}$ https://babel.hathitrust.org/cgi/pt?id=ucm.5326814403\&view=1 up\&seq=28.

${ }^{15}$ A. Sempere, Prima vereque compendiaría Grammaticae latinae Institutio, Valencia 1564. Cf. Sánchez Salor, 2003: 193-220. 
Ya hemos dicho que se trata de una reforma de las Introductiones de Nebrija. Ello se manifiesta en el hecho de que se mantiene el esquema de distribución del contenido gramatical de Nebrija. Casi todas las reformas del Arte de Nebrija respetan ese esquema.

Desde la Recognitio de 1495 el esquema de distribución del contenido gramatical en las diferentes ediciones de las Introductiones de Antonio es el siguiente:

Liber primus de primis grammaticae erudimentis.

Liber secundus de genere et declinatione et praeteritis et supinis.

Liber tertius de erotematis partium orationis.

Liber quartus de constructione partium orationis.

Liber quintus de quantitate syllabarum, metris et accentu.

La obra de Segura consta de cuatro libros ${ }^{16}$ :

Liber primus de nominum declinatione de conjugatione verbi (fol. $17 \mathrm{v}$ )

Communia praecepta pueris imbibenda (Partes de la oración)

Liber secundus de genere et declinatione nominum (fol. $53 \mathrm{v}$ )

de praeteritis et supinis verborum (fol. 64)

Liber tertius de constructione (fol. 73)

Liber quartus de Prosodia (fol. 177)

La equivalencia del esquema queda reflejada en el siguiente cuadro:

Nebrija

Liber primus de primis grammaticae erudi- Liber primus de nominum declinatione mentis (declinaciones y conjugaciones)

Liber secundus de genere et declinatione et praeteritis et supinis

Liber tertius de erotematis partium orationis

\section{Segura}

Liber secundus de genere et declinatione nominum. De praeteritis et supinis verborum

Communia praecepta pueris imbibenda (Partes de la oración) (final del libro primero)

Liber quartus de constructione partium orationis Liber tertius de constructione

Liber quintus de quantitate syllabarum, metris Liber quartus de Prosodia et accentu

El esquema es el mismo: la única diferencia está en que Segura no le concede a la definición y clasificación de las partes de oración la condición de libro independiente, sino que las incluye en la parte final del libro primero. Al no tener

${ }^{16}$ Si no decimos lo contrario los textos se toman de la edición de 1580. 
la condición de libro independiente el tema de las partes de la oración, la Gramática de Segura se queda en cuatro libros. Pero el esquema del contenido es el mismo que el de Nebrija.

\section{REFORMAS EN RELACIÓN CON NEBRIJA}

La primera diferencia está en algo que se había convertido en un tópico en la segunda mitad del siglo XVI: frente a la exagerada extensión y acumulación de adiciones que había en el Arte de Nebrija, se impone una Gramática breve y clara; al menos esos son los dos adjetivos que la propaganda repite. Segura publica por primera vez la citada obra en 1580. El esquema es, como hemos dicho, lebrijano. Pero el juicio hecho de la obra por mandato del Consejo Real observa ya la existencia en ella de aspectos que discrepan de Nebrija, pero que se presentan probabili ratione, lo de probabili ratione hace alusión a la claridad racional; el juicio o informe inicial está firmado por Mateo Otheno y dice así:

Por mandato del Consejo Real he leído los cuatro libros de Institutione Grammatica de Martín Segura; en ellos defiende, probabili ratione, muchas cosas en las que no coincide con Antonio de Nebrija ${ }^{17}$.

Y uno de los argumentos que con más frecuencia se utiliza para tratar de imponer la propia Gramática frente a la de Nebrija es que ésta era larga y prolija, mientras que la que se presenta es breve y clara. Esta idea es expuesta incluso en la Aprobación Real que aparece al comienzo:

Por cuanto por parte de vos el Maestro Martin de Segura Cathedratico de Rhetorica en la Vniversidad de Alcala, nos fue hecha relación que auiades compuesto un libro intitulado arte de Gramatica, el qual era muy vtil y prouechoso para la republica por yr (como yuan) en el los preceptos de la dicha Arte con mucha breuedad.

En el ad lectorem expone Segura su método y la diferencia del mismo en relación con Nebrija.

En primer lugar, él va a recoger en su Gramática una copia elegantium modorum, un arsenal de usos latinos elegantes, que no estaba en Antonio: fieri non posse putem ut breui tempore puer latine sciat, quamuis ingenio et memoria valeat, nisi copia elegantium modorum locupletetur (fol 9r) («pienso que no puede suceder que un muchacho aprenda en poco tiempo a hablar latín, aunque sobresalga en inteligencia y memoria, si no se enriquece con un arsenal de usos latinos elegantes»). La enseñanza de esos modos loquendi se ha de hacer de la siguiente manera:

${ }^{17}$ Mandato Regii Senatus quatuor libros Martini Segurae de Institutione Grammatica legi in quibus multa quae illi cum Antonio Nebrissensi non conueniunt, probabili ratione tuetur. 
$1^{\circ}$. Una vez que los alumnos conozcan medianamente la declinación de los nombres y la conjugación de los verbos en activa, se recogerán modos loquendi al final de la conjugación:

Is vero praeceptor, qui studuerit, ut eius discipuli fructum uberem breui ex nostris vigiliis percipiant, det operam, ut cum primum nominum declinationem tenuerint et in agenti voce primae coniugationis sint mediocriter versati, modos loquendi positos ad calcem coniugationum ediscant.

(El preceptor de Gramática que quiera que sus discípulos saquen fruto abundante en poco tiempo de mis trabajos, debe hacer que, en cuanto sepan la declinación de los nombres y estén medianamente versados en la voz activa de la primera conjugación, aprendan los giros latinos recogidos al final de las conjugaciones)

$2^{\circ}$. El maestro pondrá, tras la frase latina (modus loquendi), su traducción en castellano: quos praeceptor / positis hispanis sermonibus, quomodo illic ostenditur, exerceat (fol. 9v) («el preceptor hará que ejerciten en esos giros, traducidos al castellano, tal como están en mi texto»). Las frases latinas han de ser, en lo posible, de Cicerón. Por ello, en esta fase el maestro aprovechará para enseñar a los alumnos lo que es una cláusula o una parte de cláusula: et sumptis in manus aliquot Ciceronis epistolis, unam clausulam aut eius partem paulatim et explicatius interpretetur ("y teniendo a mano algunas cartas de Cicerón, explicará poco a poco y con detalle una cláusula o una parte de ella»).

3․ Con los modi loquendi aprendidos, hará que el alumno componga, tejiéndolos, textos más o menos amplios que deberá aprender de memoria: Docebit deinde, ex modis loquendi quos didicerunt, sumpto spacio ad cogitandum sententiam contexere eamque memoriter dicere («les enseñará después, a partir de los giros latinos que aprendieron, y tras darles un tiempo para pensar, a unirlos en frases»).

Estas y otras reformas son las que vamos a analizar.

Organizamos el material siguiendo el criterio de la ordenación del contenido en las obras, de Nebrija y de Segura, en libros o partes. De esta forma podremos comprobar en cada parte hasta dónde se mantiene Nebrija y hasta dónde es reformado.

\section{1. MORFOLOGÍA}

El libro primero de Segura se corresponde con el libro primero de Nebrija y con la primera parte de las Institutiones de Sanctius ${ }^{18}$. Se recoge en ellos el paradigma de las declinaciones y de las conjugaciones.

${ }^{18}$ Las Institutiones de Sanctius, publicadas por primera vez en 1562, son también una reforma del Arte de Nebrija, que mantiene el mismo esquema, abreviando y aclarando. 
El propio Segura presenta como original suyo lo siguiente: una nueva estructura de la categoría modo; el recurso al illustrium exemplorum usus, y una copia elegantium modorum.

\subsubsection{Estructura de la categoría modo}

En este punto no sólo se presenta como contrapunto a Nebrija, sino también a otros Gramáticos. En el libro primero, tras enseñar las cuatro declinaciones y la conjugación del verbo sum, trata de coniugatione (fol 20r); y comienza diciendo que cum in tradendis coningationibus non nibil ab usitatis praeceptis discesserim, noui instituti reddenda mihi ratio est ("como en la enseñanza de las conjugaciones me aparto algo de los preceptos al uso, he decidido explicar racionalmente mis novedades»). Y contra lo primero que arremete es contra la opinión de los gramáticos sobre el futuro imperfecto y el futuro perfecto de indicativo. Muy eruditos gramáticos, dice, han sostenido que el futuro imperfecto significa una cosa futura en desarrollo; y el perfecto, una cosa futura acabada. Segura refuta esta interpretación, diciendo que sólo hay un futuro; es el llamado imperfecto, que significa una cosa futura acabada; y pone tres ejemplos de Cicerón, que explica; el primero es de Cat. 2: extinguetur atque delebitur non modo tam adulta reipublicae pestis, verum etiam stirps ac semen malorum omnium (fol 20v). Y de este ejemplo comenta: ni extinguetur ni delebitur significan que la peste comenzará a desaparecer (incipiet deleri), sino que estará totalmente extinguida (omnino erit deleta et extincta); es decir, nada de cosa no acabada, sino que se apunta a una cosa futura acabada. Y siguen cuatro ejemplos más de Cicerón y uno de Terencio. En cuanto al futuro perfecto, dice (fol $21 \mathrm{r}$ ), in indicatiuo nullum usum habere. Y si se usa alguna vez en indicativo, tendrá el valor del futuro imperfecto: amauero en indicativo significará lo mismo que amabo; doctrina, dice, que no rechaza Linacro y que aprueba Donato cuando explica estas palabras de Terencio (Andr.), dictum et factum inuenerit aliquam causam, donde inuenerit está pro inueniet. Aduce otros dos ejemplos de Terencio y varios de Cicerón. Y termina así esta doctrina: amabo vel amauero, "yo amaré» (fol. 21v); significan, pues, lo mismo.

Moderna es su doctrina sobre el imperativo (fol 21v): se pueden dar órdenes, dice, en los tres modos: cum imperare sit commune subiunctiuo, indicatiuo et imperatiuo. Es su doctrina y lo prueba con ejemplos de Cicerón. Siglos después, funcionalistas del siglo Xx, García Calvo (1958), Mariner (1957), Lisardo Rubio (1998) entre otros, participarán de esta doctrina distinguiendo entre modo y modalidad; dar órdenes es una modalidad, concretamente la modalidad impresiva; y cualquiera de las tres modalidades, declarativa, impresiva e interrogativa, puede estar en cualquiera de los tres modos (real, potencial e irreal).

Esta preocupación por la estructura de la categoría modo determina que en la exposición de los paradigmas de los verbos insista sobre todo en los valores modales. Así, en el apartado del imperativo incluye siempre las formas del presente de subjuntivo, que, como es sabido, son aptas para expresar deseos e incluso órdenes.

Así, en el caso de la activa de amo, en el apartado dedicado al subjuntivo, tras exponer el paradigma del presente de subjuntivo, añade esto: 
Hae personae (las de presente de subjuntivo) etiam ad imperandum accommodatae, prima singulari excepta:

Ames, ama tu

Amet, ame aquel

Amemus, amemos nosotros

Ametis, amad vosotros

Ament, amen aquellos

Por poner otro ejemplo, en el caso del imperativo de lego, en pasiva, Segura recoge las formas clásicas (legere vel legitor, Se tu leydo luego o despues; Legitor, Sea aquel leido despues etc), y añade también las formas de presente de subjuntivo, que, tiene razón Segura, muchas veces tienen valores de optativo y de imperativo (Vtinam legar, Oxala yo sea leydo luego o despues; Legaris vel legare, Tu seas leydo; Legatur, Aquel sea leydo etc.).

En el caso, pues, del tiempo y del modo introduce doctrina nueva en la reforma de Nebrija. En lo que se refiere al tiempo, rechaza la distinción aspectual en el caso del futuro; $y$ en el caso del modo, insiste en los valores de modalidad que hay en algunos modos.

\subsubsection{Illustrium exemplorum usus}

Segura es fundamentalmente ciceroniano. Cuando recoge illustrium exemplorum usus, la mayoría de los ejemplos son de Cicerón. Antes hemos visto que para demostrar que el futuro imperfecto indica una acción acabada recurre a cuatro ejemplos de Cicerón y uno de Terencio.

En el resto de este primer libro sobre Morfología, cuando recurre a ejemplos, es Cicerón el preferido.

\subsubsection{Copia elegantium modorum}

Segura convierte en motivo fundamental de su obra la adición de ejemplos latinos, sobre todo de Cicerón; se trata tanto de modismos (modi loquendì), como de frases sacadas de Cicerón y otros clásicos. Esto lo anuncia desde un punto de vista programático, y lo cumple. Sobre todo en la primera edición de 1580. En ella los modismos y ejemplos son muy numerosos.

La incorporación en la Gramática de frases latinas cortas para que los alumnos las aprendan en latín con su significado en castellano estaba ya en el Arte de Nebrija; con una diferencia en relación con Segura: que Nebrija recogía la copia en capítulo aparte, mientras que Segura va incorporando las frases al hilo de los preceptos.

La copia verborum o modorum no tiene otra finalidad que la de enseñar a los muchachos a hablar latín; se les enseñan frases con las que pueden empezar a hablarlo en situaciones comunes y ordinarias de su vida.

Dos cuestiones importantes se plantearon en el siglo XVI en relación con la enseñanza del latín por medio de tratados: la primera se refiere al propio hecho de hablar 
latín; a este respecto hay dos posturas enfrentadas: por un lado, los gramáticos racionalistas, al frente de los cuales se coloca el Brocense, que sostienen que no se debe hablar latín porque hablándolo lo corrompemos; y es que no podemos lograr la perfección y elegancia de los clásicos, y, por ello, cualquier cosa que digamos en latín la diremos en un latín corrupto y consiguientemente es mejor no hablarlo. Por otro lado, están los gramáticos escolares, los jesuitas fundamentalmente desde finales del XVI y a lo largo de todo el XVII, cuya meta es que los muchachos aprendan a hablar latín, bueno o malo, pero que se entienda.

Segura se coloca en esta segunda posición. Él sí quiere que los alumnos aprendan a hablar latín; y para escapar de las críticas de los racionalistas y sostener, en contra de ellos, que sí se puede hablar una latín elegante, él selecciona modi elegantes; es decir, frases latinas elegantes de los autores clásicos, especialmente de Cicerón. De esta forma salva la dificultad que ponían Sanctius y sus seguidores de que no se podía hablar un latín elegante, y vuela, o eso pretende, muy por encima de los que enseñan latín por medio de multitud de frases latinas no clásicas; muchas veces, inventadas. Él pretende enseñar a hablar un latín elegante.

Esta preocupación por la elegancia se manifiesta también en el hecho de que introduce doctrina relativa a la Sintaxis figurata. La figuras de construcción, por ello se llama figurata, intervienen en el paso que va desde el esquema mental de una frase a su realización sintáctica; la frase a nivel de esquema mental tiene todos los constituyentes que debe tener; los tiene en el orden en que deben estar; y esos constituyentes desempeñan la función que, por regla general, les asigna la Gramática. En la realización sintáctica de la frase puede suceder que falte algún constituyente de los que estaban en el esquema mental (elipsis), que se añada alguno que no estaba (pleonasmo), que no aparezcan en el orden en que estaban en la mente (hipérbaton); o que un constituyente no desempeñe la función que normalmente desempeña (enálage). Estas son las llamadas figuras de construcción, ya que intervienen en la construcción sintáctica que se genera a partir del esquema mental. La función más importante de la figura de construcción es generar elegancia en las frases realizadas a nivel sintáctico. Juegan, pues, un papel importante en el concepto de elegancia.

Pues bien, a este respecto Segura es novedoso en el siguiente sentido: Expone la regla gramatical; recoge después ejemplos relacionados con la regla; $y$, en aquellos ejemplos en los que es apreciable alguna figura de construcción sintáctica, advierte de esa figura en el margen. Lo anuncia él mismo en la primera observación que hace al principio del libro de la Sintaxis:

Et si illa exempla quae superius posita sunt ad orationem figuratam spectent, de qua dicemus inferius, quia passim in hoc genus incurrimur, constitui obiter attingere (73v). (Y si los ejemplos que pongo en el texto pertenecen a oraciones en las que ha intervenido alguna figura, de la cual hablaremos más adelante, ya que con mucha frecuencia recurrimos a ellas, he decidido anotarlo para que se vea).

Y así lo ha hecho. Entre los ejemplos de dos o más sujetos para un solo verbo recoge este:

Justitia, abstinentia, clementia tui Ciceronis reuiuiscunt (73r). 
Y en nota aparte recoge la referencia ( 4 att. 5) y advierte que es una syllepsis. La silepsis en este caso es una variante de la elipsis, ya que se elide el verbo en los dos primeros sujetos. Evidentemente es mucho más elegante decir Justitia, abstinentia, clementia tui Ciceronis reuiniscunt que Justitia reuiuiscit, abstinentia reniuiscit, clementia tui Ciceronis reuiuiscit.

Otro ejemplo es:

Aliquando sic, mens consilium ratio in senibus est (73v).

Y en el margen de nuevo la referencia (7 senect.) y la advertencia de que se trata de un Zeuma, que no deja de ser en este caso una variante de la elipsis.

La intención, pues, de Segura es hacer una reforma del Arte de Nebrija, abreviando sobre todo su contenido, pero también busca enseñar a los muchachos a hablar un latín elegante enseñándoles modismos y frases sacadas de autores latinos. Es muy probable que recibiera críticas por esto último (no hay que olvidar que estamos en la década en que el Brocense defiende con fuerza que no se debe hablar en latín), y por ello en la edición de 1589 aligera mucho la parte antes dedicada a copia de frases y modismos. Iremos viendo esto último a medida que vayamos analizando la obra.

Tras el paradigma de amo, de la primera conjugación, añade la siguiente

(fol. 26) Exercitatio.

Una vez aprendida la voz activa del verbo amo, amas, el estudiante aprenderá las siguientes y otras fórmulas usadas de la primera conjugación:

Sententiam memoriae mando, yo decoro la sentencia

Magnam gloriam comparo, gano grande honra

Virtutem adamaui, ame en extremo la virtud

[El maestro hará que el alumno haga ejercicio repitiendo la frase poniendo delante el español:

Yo decoro la sentencia, Ego mando sententiam memoriae

El niño decora la sentencia, Puer mandat sententiam memoriae.

Después repetirá las frases cambiando el sujeto a «nosotros» «vosotros», y luego cambiando el tiempo del verbo:

Los niños decoraran la sentencia, Pueri mandabunt sententiam memoriae

Después le hará componer un pequeño discurso;

El niño decora la sentencia, ama la virtud, y ganara honra, Puer mandat sententiam memoriae, adamauit virtutem, et comparabit gloriam]

El niño hará así ejercicios de todas las formas hasta que adquiera agilidad en todas las fórmulas del habla [y no le hará daño haber aprendido muchas fórmulas] ${ }^{19}$.

${ }^{19}$ Lo que va entre corchetes no aparece en la edición de 1589. 
Como ya hemos dicho, es posible que las críticas al método le hicieran entrar en moderación y reducir el número de frases latinas que los alumnos deben aprender.

Tras el paradigma de la voz pasiva de la primera conjugación, de nuevo otra exercitatio:

(fol. 29) En ese punto el niño aprenderá de memoria muchas frases latinas y las convertirá en voz pasiva:

Socrates eloquentiam exagitat, Sócrates persigue la eloquencia

Tu recuperas amissionem bonorum, Tu recuperas la perdida de los bienes

Dux animos militum instaurat, El capitán renueva los animos de los soldados

[Animos vobis dedi, He os dado animos] ${ }^{20}$

En pasiva así:

Eloquentia exagitatur a Socrate, amissio bonorum recuperatur a te, animi militum instauratur a duce, animi vobis dati sunt.

Tras el paradigma de la segunda vuelve con lo mismo:

(fol. 32) Exercitatio

Será también útil que los muchachos aprendan algunos modos loquendi de la segunda conjugación:

Vocem, memoriam exerceo, Exercito la voz, la memoria ${ }^{21}$

Misericordiam commoneo, Mueuo misericordia ${ }^{22}$

Obtineo causam, Alcanço el pleito ${ }^{23}$

Id habet omnes numeros, Esto tiene la perfeccion

[Habeo rationem absentis, Tengo respeto al ausente]

Habeo multarum rerum vsum, Tengo vso de muchas cosas

[Habes animum tanqam arcum intentum, Tienes el animo como ballesta armada ${ }^{24}$ Tibi victum praebeo, Doyte mantenimiento ${ }^{25}$

Operam praebeo, favorezo a mis amigos ${ }^{26}$

Illi hoc munus debeo, Deuo aquel este beneficio ${ }^{27}$

Luego, el maestro enseñará a los alumnos a componer un texto de esta forma:

El niño que exercitare la memoria, y la voz, y tuuiere vso de muchas cosas, alcançara el pleyto, Puer, qui exercuerit memoriam et vocem et habuerit vsum multarum rerum, obtinebit causam

\footnotetext{
${ }^{20}$ En este caso, en la edición de 1589 sólo suprime esta fórmula.

${ }^{21}$ En el margen, I Or.1.

${ }^{22}$ En el margen 3 Ver. 3.

${ }^{23}$ En el margen, 9 Amic.

${ }^{24}$ En el margen, 7 Sene.

${ }^{25}$ En el margen, 8 Ora.

${ }^{26}$ En el margen, 9 Clar.

${ }^{27}$ En el margen, 2 Or. 3.
} 
[Y alcançara lo que quisiere de su maestro, Et impetrabit a magistro quod velit $\mathrm{Al}$ qual despues sustentara la republica, Cui res publica postea praebebit victum Porque tuuo su animo tan atento como el arco armado, Quoniam animum habuit tanquam arcum intentum] ${ }^{28}$.

Lo mismo hace tras el paradigma de la segunda conjugación. Añade una exercitatio en la que pone, para que los alumnos las aprendan, frases cortas de Cicerón, con su correspondiente traducción en español (p. e. Epistolam lacrymis deleui, «Borré la carta con lágrimas», fórmula que ha tomado, indica en el margen, de Fam. 15, fol. 5v).

Y lo mismo hace tras los paradigmas de la tercera y cuarta conjugación.

De manera que ya en la primera parte de la Gramática, la dedicada a los paradigmas de declinaciones y conjugaciones, ocupa un espacio considerable el método de enseñar a hablar latín a partir del aprendizaje de frases latinas con su equivalencia en español y a iniciar al alumno en la composición latina. Enseñar frases y usos latinos era propio ya de los tratados de Copia, el más importante de los cuales fue el de Erasmo; el método seguirá siendo muy utilizado por los jesuitas a finales del siglo XVI y a lo largo de todo el siglo XVII; los jesuitas darán también gran importancia a la composición en latín. Segura, en su Gramática de 1580 dedica una buena parte ya del libro primero al aprendizaje de frases y a comenzar la composición en latín. En la edición de 1589 reducirá mucho el número de ejemplos. Ya hemos dicho que posiblemente por las críticas de las que él mismo habla en el Ad lectorem de esta edición.

\subsection{Pequeño apartado Sobre las Partes de la oración}

El esquema de Nebrija incluía en su Arte un libro, el tercero, que trataba de las partes de la oración. Lo exponía mediante el procedimiento de preguntas y respuestas, que era un procedimiento al que se le suponían ciertas ventajas pedagógicas. Nebrija trata este asunto tras haber expuesto, en el libro I, los paradigmas del nombre y del verbo, y, en el libro II, las reglas del género de los nombres y de los pretéritos y supinos del verbo. Este orden de Nebrija parece lógico: tras los paradigmas del nombre y del verbo, trata de dos cuestiones que tienen que ver, respectivamente, con el nombre y con el verbo: el género, que es la categoría más complicada del nombre porque en ella se mezclan y confunden forma y significado; y los pretéritos y supinos cuyos temas no coinciden exactamente con los del presente y, consiguientemente, es necesario conocer, para conocer completo el paradigma del verbo.

${ }^{28}$ De nuevo aquí, en la edición de 1589 , suprime todo lo que hemos recogido entre corchetes. Parece que las críticas le han obligado a suprimir una buena parte de ejemplos y modos loquendi. Precisamente el ingrediente que él presentaba como muy importante en la edición de 1580. 
Segura, sin embargo, coloca esta doctrina sobre las partes de la oración inmediatamente después de la Morfología del nombre y del verbo y antes del libro dedicado al género del nombre y a los pretéritos y supinos. Y, además, no concede a esta parte la categoría de libro, cosa que sí hacía Nebrija y hace también Sanctius en sus Institutiones.

Introduce esta doctrina de las partes de la oración bajo el epígrafe Communia praecepta pueris imbibenda («Preceptos comunes que deben conocer muy bien los niños»). Es exactamente lo mismo que venía apareciendo en las Introductiones de Nebrija de finales del siglo XV; es lo que hace Sanctius en sus Institutiones de 1562 y ediciones siguientes; y lo mismo que hace De la Cerda en el Arte Reformada de 1601. Todos los manuales de la época, que pretenden una reforma de las Introductiones de Nebrija basada en la brevedad y claridad, tienen la misma estructura: las mismas partes, pero tratadas de forma más breve. Segura y Sanctius son relativamente extensos en esta parte, pero se diferencian en que Sanctius se extiende en la explicación y clasificación de cada una de las partes, sobre todo en el caso del nombre y del verbo, mientras que Segura se extiende en otras cuestiones, sobre todo en la aportación de modi loquen$d i$, que, como ya sabemos, es uno de los objetivos fundamentales de Segura.

En primer lugar se extiende en la explicación de la función de los casos, pero añadiendo ejemplos:

Qui agit nominatiuo, quod ago accusatiuo conuenit, ut discipulus magistrum obsernat, Respecta el discipulo al maestro.

Cuius res est in genitiuo, vt Ciceronis eloquentis adumbraui.

Cui damus vel eripimus aliquid in datiuo, vt Pueris leges damus.

Quem vocamus vocatiuo, ve Marce fili.

Sin, con, en, por hispane et vnde discedimus, in ablatiuo. Laus etiam et vituperio, vt tu es magna prudentia vel prudentiae.

Praepositio cum coniungitur comiti, non instrumento, dicesque Cum illo negotium contraho, et hunc lapide percussi, non cum lapide (fol. 50v)

(El que hace va en nominativo; ese verbo «hacer» exige acusativo, como en discipulus magistrum obseruat, Respecta el discípulo al maestro.

Aquél del cual es algo va en genitivo, como Ciceronis eloquentis adumbraui.

Al que damos o quitamos algo, va en dativo, como Pueris leges damus.

Al que llamamos, en vocativo, como Marce fili.

Los complementos con las preposiciones españolas sin, con, en, por y los que indican el lugar de donde partimos van en ablativo; también la alabanza y el vituperio, como tu es magna prudentia vel prudentiae.

La preposición cum se utiliza para indicar el acompañante, pero no el instrumento, y se dirá Cum illo negotium contraho, y hunc lapide percussi, pero no cum lapide).

Como se puede ver, la función de los casos se define con las preguntas quién, qué, de quién, para quién, a quién llamamos. Este es un recurso que estaba ya en las Gramáticas antiguas. Pero, aparte de esta concesión a la tradición, sigue en su preocupación por enseñar a los muchachos modos loquendi. Obsérvese que, en efecto, todo gira en torno a enseñar al alumno a construir frases latinas correctas: tras cada caso, añade un ejemplo de frase latina. Y ello es evidente sobre todo en el caso del ablativo, donde la formulación de la regla parte del español; se enseña a construir frases latinas 
a partir de usos españoles que supuestamente deben ser conocidos por los alumnos; así, se enseña que aquellos nombres que en español llevan las preposiciones sin, con, en se construyen en latín en ablativo; y también se ve esa tendencia a enseñar a poner usos españoles en frases latinas en la observación final en la que advierte que la preposición cum latina se utiliza para significar compañía, pero no para significar instrumento; se dice hunc lapide percussi, y no hunc cum lapide percussi.

En segundo lugar, al final de este apartado Segura añade una Perbreuis quedam sintaxis verbi (fol. 51v) ("Una muy breve sintaxis del verbo»), donde lo que hace es poner ejemplos de frases en las que aparecen usos especiales de los diferentes casos. Así, para el nominativo aporta las frases Ille euasit summus orator, tu indicatus es hostis, "Aquel salió gran orador», "tu fuyste tenido por enemigo», en las cuales se enseña el uso del nominativo como atributo de una frase tras verbos que aceptan atributo. Para el genitivo, trae ejemplo de genitivo tras verbo de compasión, Ego misereor tui, «Tengo compasión de ti»; y buena prueba de que se trata de enseñar a construir frases latinas desde el español es el hecho que junto a la frase anterior, pone otra en la que en español se usa también "de» más nombre, pero no se corresponde en latín con un genitivo, sino con un ablativo: Tu consiliis indiges, "Tu tienes necesidad de consejo». Para el dativo, recoge las frases Vtilitati servio, Studiis obsequor, "Miro por el prouecho", "Obedezco a tu voluntad». Para el acusativo, habeo delectum, sequor consilium, "Hago gente», «sigo el consejo», que son modismos latinos. Y para el ablativo, ejemplo de frases sin preposición, Flagras inuidia, Vteris sermone, "Estas muy envidiado", "Vsas de platica»; y con preposición, Profeci in literis, Versor in periculis, «Aprouecho en las letras», «ando en peligro».

Nada de esto hay en la parte dedicada a las partes de la oración en la edición de 1589. En esta edición se extiende, siguiendo el ejemplo de las Institutiones de Sanctius, en la explicación y clasificación de cada una de las partes, sobre todo en el caso del nombre y del verbo; y también de la preposición. Siguen surtiendo efecto las críticas que sin duda recibiría después de la primera edición de 1580 y elimina todo lo que tiene que ver con los modi loquendi; es decir, con enseñar a los alumnos frases latinas a partir de frases españolas e introducirles en la composición latina. Y en lugar de ello, sigue el esquema que seguía Sanctius en sus Institutiones desde 1562. En la lucha que mantienen en la parte final del siglo XVI Sanctius y otros gramáticos racionalistas, que defendían que no se debía hablar latín, contra los que defendían la necesidad de hablarlo, entre los cuales se encuentran los jesuitas, Segura comenzó en el grupo de los segundos, pero luego se pasó al de Sanctius y los racionalistas. Hay gramáticos que siguen el camino contrario: comienzan en las filas de los racionalistas y luego se pasan a las de los que pretenden enseñar a hablar latín por medio de tratados como las Ianuae linguarum. Es el caso del portugués Reboredo ${ }^{29}$.

${ }^{29}$ Amaro de Reboredo (1580/85-1653 post) publicó en 1615 su Verdadeira Grammatica latina para sem bem saber en breve tempo, scritta na lingua portuguesa com exemplos na Latina, donde se presenta como seguidor de Sanctius. En el Prologo de la misma dice que, entre las Gramáticas excesivamente 
Siguiendo el orden propuesto en las Introductiones latinae de Nebrija, las Gramáticas que se presentan como breves y claras en la segunda mitad del XVI colocan, tras los paradigmas del nombre y del verbo y tras la pequeña parte dedicada a la definición y clasificación de las partes de la oración, un apartado o libro que trata del género de los nombres y del pretérito de los verbos.

En Nebrija este libro estaba escrito en versos hexámetros. Sanctius en sus Institutiones latinae lo compone también en hexámetros. En hexámetros siguen en el Arte reformada del padre Juan Luis de la Cerda.

Segura, sin embargo, lo escribe en prosa y explica por qué no lo hace en verso con estas palabras:

Cum perspicuitas in tradendis praeceptis sit maxima virtus eamque stricti carminis numeri vehementer saepe perturbent, maxime vero in materia tam spinosa et ieiuna,... imitari institui Donatum aliosque huius sectae scriptores, et meas praeceptiones ex vinculis versuum eximere (fol. 53).

(Dado que la claridad es la mayor virtud en la enseñanza de los preceptos y que esa claridad queda frecuentemente muy perturbada por la rigidez del ritmo del verso, y sobre todo en materia tan áspera y seca, decidí seguir a Donato y a otros escritores de su línea y librar mis reglas de las ataduras del verso).

Tras esto declara cuál va a ser el procedimiento de exposición del tema: expondrá primero las reglas generales; después, las reglas del género del nombre a través de las cinco vocales; ilustrará cada regla con ejemplos. Lo usos que se salen de la norma general y son frecuentes, los recorrerá uno por uno. Los menos frecuentes, los expondrá en letra pequeña al final de la regla. Finalmente tratará del genus dubium:

\footnotetext{
largas y las demasiado cortas, él ha escogido un camino intermedio; en efecto, huyendo de los dos extremos, ha escogido, de lo mucho, lo necesario; y de entre los muchos gramáticos, imita al mejor, que es Sanctius; aunque, lo hace abreviando y facilitando la materia. Reboredo escribe, pues, primero una Gramática de corte sanctiano, aunque muy breve. Tan breve que al final de la misma añade unas aparentes respuestas a objeciones, que son en realidad el desarrollo de capítulos fundamentales de la Gramática racional. Al acabar su Grammatica, debería tener quizás mala conciencia Reboredo por dos razones: en primer lugar, por no haber compuesto una Gramática sanctiana un poco más densa y extensa de lo que había resultado su Grammatica; y, en segundo lugar, porque se ha confesado al principio de ella seguidor de Sanctius y sabe que su futuro gramatical está, no en la búsqueda de causas de la lengua, que era el objetivo de Sánchez, sino en algo contra lo que el maestro salmantino había luchado: hablar latín; sabe, en efecto, que él va a terminar proponiendo un método práctico para enseñar latín al estilo de una Ianua linguarum. En efecto, en 1619 publica su Methodo gramatical para todas as linguas, que tiene tres partes, la segunda de las cuales (pp. 79-181) recoge las 1141 frases de una Ianua linguarum que los jesuitas irlandeses de Salamanca publicaron a finales del siglo XVI; Reboredo añade números y notas interlineales. La tercera (pp. 182-241) es una Copia verborum, que es ingrediente fundamental de las gramáticas escolares que pretenden enseñar a hablar latín. Empezó en la Gramática racional y terminó en la gramática escolar para enseñar latín a través del léxico y de frases.
} 
In genere hoc institutum tenebo: canones quosdam tradam generales, deinde genus nominis ad vocales quinque reducam; singula praecepta exemplis illustrabo. Et quae eximuntur ex generali praecepto et magis in usu sunt, continenter decurram. At vero minus vsitata, literis minoribus distincta, ad praecepti calcem adiungam. Postremo genus dubium conectabor (Ibid.)

(En el caso del género observaré este procedimiento: daré unas reglas generales; después reduciré el género del nombre a las cinco vocales ${ }^{30}$; ilustraré cada regla con ejemplos. Y los usos que se salen de la regla general y son, sin embargo, muy usuales, los expondré uno a uno. Pero los menos usuales, los distinguiré poniéndoles en letra más pequeña al final de cada regla. Finalmente seguiré con el genus dubium).

En este punto los ejemplos aducidos no son tanto de Cicerón, como ha ocurrido hasta ahora, como de poetas, Virgilio, Horacio, Ovidio. Por otro lado, hay que decir que Nebrija distingue entre

- reglas del género en virtud del significado de las palabras

- reglas en virtud de la terminación.

Segura, sin embargo, distingue entre

- reglas generales del género

- reglas en función de la vocal final de la palabra.

Segura convierte, pues, las reglas del género en virtud del significado de Nebrija en reglas generales del género. Parece que Segura da más importancia en el género al significado de las palabas que a la terminación. Es una reforma más al Arte de Nebrija. Y se aparta también en ello de Sanctius quien, en sus Institutiones, que, como hemos dicho, son una gramática más de Nebrija reformada en la segunda mitad del siglo XVI, llega a decir que «sólo la existencia de los adjetivos justifican la creación del género en los sustantivos; y es que, si los adjetivos no existiesen, el género no sería necesario" ${ }^{31}$; Sanctius no da, pues, importancia al significado en el caso del género, y sólo se la da a la forma, ya que, si existe el género, es para facilitar la identificación de la concordancia entre adjetivo y nombre. Segura, sin embargo, considera al significado de las palabras como base natural fundamental para el género.

Rompe también Segura con el esquema tradicional de Nebrija en lo siguiente: Antonio sólo trataba del género de los nombres y del pretérito-supino; Segura introduce, entre el género de los nombres y el pretérito-supino una parte, corta, sobre los casos. Parece lógico esto de Segura. Y es que la inclusión de este apartado,

${ }^{30}$ Es decir, reglas sobre el género de los nombres cuyo tema es alguna de las cinco vocales.

${ }^{31}$ Propter sola adiectiua reperta esse in substantiuis genera. Nam si adiectiua non essent, nibil esset opus generibus (Verae breuesque Grammatices latinae Institutiones, Salamanca 1595, fol.27v). 
tras las declinaciones de los nombres y las conjugaciones de los verbos, sólo se entiende si se piensa que el gramático pretende explicar las categorías del nombre y del verbo que presentan características morfológicas especiales, pero sólo aquellas que considera que necesitan explicación: el género en el caso del nombre, ya que esta categoría no está perfectamente sistematizada desde el punto de vista morfológico, y el pretéritosupino en el caso del verbo, porque en el verbo latino la morfología temática del pretérito y supino no es la misma que la de los temas de presente. Es lo que hacen Nebrija en sus Introductiones y Sanctius en sus Institutiones; y lo hacen, además, en verso. Se olvidan, en relación con el nombre, del número y del caso. En relación con el verbo, regulan la formación de los temas de perfecto, pero no hablan de los temas de presente.

Segura trata de llenar al menos una de estas lagunas: habla del género del nombre y también del caso; no habla del número porque morfológicamente esta categoría no presenta serias dificultades. Y en lo que se refiere al caso sólo trata eos casus in quibus vltimae syllabae dissimilitudo existit («aquellos casos en los que la última sílaba tiene variantes»), es decir aquellos casos que morfológicamente ofrecen más dificultad. Por ejemplo:

Prima declinatio desinit in as, es, a, am, e Graecum; sed es, e, retinent illam vocalem; Anchises tamen in vocatiuo et ablatiuo habet a.

...

Datiuus pluralis in is aliquando in abus: deabus (fol. 62r)

(La primera declinación termina en as, es, a, am, y e griega; es y e conservan aquella vocal griega; Anchises, sin embargo, tiene $a$ en el vocativo y en el ablativo.

...

El dativo del plural termina en $i$, a veces en abus, como en deabus).

Esto es lo que dice de la morfología de los casos de la primera declinación. No es mucho, pero es un indicio del interés de Segura por cubrir toda la morfología nominal.

En las reglas sobre la formación de los diferentes temas de perfecto no recurre prácticamente a ejemplos de autores clásicos. Se ve que no tiene mucho interés en que los muchachos aprendan a construir frases jugando con los temas de perfecto.

De la misma forma que en el caso de las partes anteriores de la Gramática, también en esta se produce un cambio importante en la edición de 1589 en relación con la de 1580. Si en la de 1580 renunciaba a exponer las reglas en verso, como había hecho y estaban haciendo Nebrija y Sanctius, en la de 1589 recurre a un camino intermedio entre el verso y la prosa. Lo dice él mismo en la introducción a esta parte que, por supuesto, es diferente de la introducción de 1580:

Editione prima huius libelli ex vinculis carminum exemi praecepta, ne illorum obscuritas captui puerorum officeret; quia vero, quae habent rythmum ediscuntur facilius et retinentur memoria firmius, institui non versum efficere, sed numero decem et sex syllabarum circiter singulos literarum ordines concludere; quo simul, si possem, carminis obscuritatem vitarem et perspicuitati dandi praecepta consulerem. Tu aequi bonique facies (fol. 50v). 
(En la primera edición de este libro liberé a las reglas de las ataduras del verso, para que la oscuridad de éste no fuera un obstáculo para la comprensión por parte de los niños. Pero, como es cierto que lo que tiene ritmo se aprende más fácilmente y se retiene mejor en la memoria, he decidido, no hacer verso, sino recoger cada grupo de regla en dieciséis sílabas más o menos. Considéralo justo y bueno).

Y empieza así:

Viri picti et veri nomen, masculum dicito semper

fluuii, venti, mensis, montis, illis adiungito quoque,

testis erit Michael, Mars, Petrus, agricola, Baetis.

(Los nombres de varón, ya pintado, ya real, los dirás siempre en masculino;

a ellos añadirás también los nombres del río, del viento, del mes, del monte;

ejemplos de ello son Miguel, Marte, Pedro, agricultor, Betis).

Se trata, efectivamente, de expresiones de dieciséis sílabas con ritmo acentual trocaico y cláusula dactílica. La verdad es que no se alejan mucho de los versos de Nebrija y de Sanctius, de manera que viene a caer en el defecto que trataba de evitar en 1580 . De nuevo ha cedido ante las críticas. Por otro lado, ocurre que, junto a estas reglas, escritas de esta forma, acumula observaciones complicadas, que no favorecen en nada a la pedagogía.

Por lo demás, sigue manteniendo la clasificación de 1580: reglas generales, por un lado, y reglas de terminación por otro.

\section{SINTAXIS}

La primera cuestión que plantea Segura gira en torno a las diferentes formas en que se puede exponer el contenido de una Sintaxis. En el libro de la Sintaxis recoge, en efecto, un capítulo titulado De duplici ratione sintaxis et quam autor sit secutus (fol 69v) («Sobre la doble forma de presentar la Sintaxis y sobre la forma que sigue el autor»). Habla, pues, de dos formas de explicar la Sintaxis:

$1^{\text {a }}$. Una es quae casus persequitur, es decir la que organiza el material sintáctico siguiendo como criterio los casos del nombre; es en la que parece pensar, dice Segura, el Autor octo partium.

¿Quién es el Autor octo partium? El propio Segura dice que este tipo de organización del material sintáctico varia genera verborum in uno casu permiscet, es decir, se distinguen los casos, pero se mezclan los tipos de verbos. Pues bien, autores que escribieron un De octo partium orationis liber fueron Erasmo y el padre jesuita Álvarez.

Erasmo en su Libellus de octo partium orationis ${ }^{32}$ organiza el material sintáctico siguiendo el criterio de los casos; comienza así:

${ }^{32}$ Libellus de constructione octo partium orationis (ed. M. Cytowska), en Opera omnia Desiderii Erasmi Roterodami, I-4, Amsterdam 1973. 
De constructione verbi cum nominativo.

Nominatiuus ante verbum.

Omne verbum antecedit nominatiuus agentis seu patientis eiusdem numeri et personae. Ut Ego doleo, Tu gaudes, illi rident, nos fallimur.

Appendix I. Prima et secunda persona ferme non explicantur nisi discretionis aut emphasis causa, ut Nos accusauimus...

Appendix II. Aliquoties orationis pars nominativi vice ponitur, ut Dolet mihi quod res non cesserint tibi ex sententia

De constructione verbi cum genitivo.

De constructione verbi cum dativo

...

De constructione verbi cum accusativo

De constructione verbi cum ablativo

El padre Álvarez, antes de sus De institutione grammatica libri III, publicados en 1572, había editado, quizás ya en 1557 por primera vez, un De constructione octo partium orationis. Se trata de un opúsculo, de poco más de 20 páginas.

De manera que el autor al que se refiere Segura puede ser o bien Erasmo o bien el jesuita Álvarez.

$2^{\text {a }}$. Otra es la que genera verborum distinguit. Esta es, dice Segura, la que él va a seguir, quia planior est et magis puerorum inteligentiae accommodata (fol. 69).

Expone la ordenación de material que va a seguir en el folio siguiente:

Hunc ordinem tenebo.

Principio verba in generales quasdam rationes includam; deinde modos loquendi elegantiores, idemque significantes, si facultas illorum sit, in qualibet specie colligam: ex quibus duos tresve verborum comprehensiones breui contexam. Illasque cum modis loquendi qui antecesserint, puer memoriae mandet reliquos in aliud tempus reseruet. Postremo illustriora verba, quibus nominibus coniungat Cicero, accuratius ostendam, ut puer praecepto cognito, in Ciceronis usu versetur (fol 69v).

(Seguiré este orden

$\mathrm{Al}$ principio clasificaré los verbos en especies generales; después, recogeré en cada una de las especies los giros latinos elegantes en la medida que signifiquen lo mismo; a partir de esos giros construiré dos o tres oraciones breves. El niño aprenderá de memoria esas oraciones junto con los giros correspondientes a ellas; el resto de giros lo dejarán para otro momento. En relación con los más famosos de esos giros les mostraré los verbos con los que Cicerón une cada nombre, para que el alumno, una vez conocido el precepto, verse en el estilo ciceroniano).

La organización, pues, del material sintáctico gira en torno al verbo y sus especies; otra forma de organizarlo era, como hemos dicho, en torno a los casos. Es más tradicional la primera forma: todo gira en torno al verbo y sus especies; es la de Nebrija; 
más moderna es la organización en torno a los diferentes casos; esta última es la que sigue Sanctius en su Minerva; en las Institutiones, sin embargo, Sanctius mezcla los dos criterios.

En este punto, pues, Segura es continuador de Nebrija con la siguiente diferencia: despoja a esta parte de todos los añadidos y comentarios que se habían acumulado en esta parte en las Introductiones de Nebrija.

A cambio, añade frases latinas a modo de ejemplos, fundamentalmente ciceronianas. En efecto, en esta parte dedicada a la Sintaxis sigue insistiendo en el objetivo que persigue: enseñar a los muchachos usos y modos elegantes de hablar latín. Y es que, además de las reglas, intenta también enseñar a hablar latín; y un latín clásico, fundamentalmente ciceroniano. De ahí su insistencia en la enseñanza de frases latinas auténticas, entre las que se encuentran los modismos (modi loquendi) y los usos de autores ilustres (illustrium exemplorum usus).

Cuando expone el método que va a seguir a la hora de exponer la Sintaxis, Segura lo explica. Dice, en efecto, que hay dos criterios de los que ya hemos hablado: uno es seguir el criterio de los casos; se trataría de organizar el material sintáctico de acuerdo con los usos y funciones de los casos; otro es seguir las clases de verbos. Segura anuncia que se va a acoger a este segundo criterio. Y anuncia que junto a las reglas sintácticas va a añadir modos loquendi latinos y ejemplos de autores ilustres; todo ello en aras de la elegancia y del ornato:

Si yo presentara los preceptos desnudos, sin abundantes y elegantes ejemplos (como se ha hecho hasta ahora), no dudo de que a los sabios les parecería mi Gramática ayuna e inacabada; pero si, junto a los preceptos, se ponen la riqueza y la abundancia de ejemplos de los mejores autores, mi obra será quizás perdonada y yo veré que el esfuerzo y el trabajo han sido útiles para la sociedad ${ }^{33}$.

Las frases de Cicerón eran ya muchas en la primera parte de Morfología. En la Construcción o Sintaxis anuncia que su fuente principal de ejemplos será Cicerón. Y lo cumple. Al comienzo mismo encontramos tres:

Praecepta communia.

Verbum personale finitum antecedit nominatiuus, vel eius loco oratio aut infinitum: vt ego caeteris satisfacio (fam. i), dolet mihi quod tu non stomacheris (2 ep. ad br.), vacare culpa magnum solatium est (3 fam. i) (fol.73).

Y así continúa a lo largo de toda la Sintaxis.

${ }_{33}$ Si praecepta traderem nuda ab vbertate ( $v$ t hactenus factitatum est) non dubito quin doctis ieiuna videretur et inchoata (su Gramática); si vero illi, vbertas et copia optimorum autorum accesserit, aliquid fortasse habebit absolutionis et nos videbimus studium et officium publice vtilitati praestitisse (p. 69). 
En el contenido de la Sintaxis hay elementos novedosos y modernos junto a doctrina tradicional. Tradicional es la clasificación de los verbos en verbo sustantivo (sum) y verbo accidente (amo); y la clasificación en personales e impersonales, y también la clasificación de los personales en activos, pasivos, neutros y deponentes. Tradicional es también la división de los activos en especies: la primera especie es la de aquellos que exigen un acusativo. Los ejemplos son una verdadera copia verborum sacada de Cicerón:

(margen izdo.)

Referencia
Ejemplos

Rego rem publicam (1 or. 1); gero remp. ( 2 mil.); administro remp. (3 fin. 3); guberno remp. (4 ros. am.); eius clauum teneo (7 phi. 7); gubernacula tracto. (margen der.) en español

Obsidet, labefactat, oppugnat, Ille remp. obsidet, labefactat, Aquel cerca, maltrata, bate, affligit (arus. 1); lacerat ( 2 red. opugnat, affligit, lacerest, aflige, destruye, oprime y es 5); opprimit (3 phi. 6) prodit opprimit, prodit. (4 diuin. 2)

Siempre que el número de ejemplos aportados es considerablemente amplio, los agrupa bajo un epígrafe que es una sola palabra, tras la cual puede estar o bien sólo la palabra, o bien un concepto; con ellos se pueden formar frases latinas con los verbos activos que llevan acusativo: los ejemplos anteriores están bajo el epígrafe rempublicam; y siguen los epígrafes legem, animos, impetum, illum. Cuando el número de ejemplos no da para ello, no los agrupa bajo ninguna palabra, pero los coloca en función de su relación semántica con los diferentes grupos. Todo ello de acuerdo con el principio de que los alumnos aprendan frases latinas con las que se pueda decir la misma idea pensada en español y conecten y relacionen unas con otras. Así, en el caso de impetum como complemento directo de un verbo activo de la primera especie hay ejemplos como furorem, vim debilito, cohibeo, retardo, frango, reprimo, comprimo, extinguo, o como domitas habeo libidines, frango, refreno cupiditates, o Caesar gentes barbaras immanitate recidit, repressit, contriuit, vicit, domuit, subegit, dissipauit, fudit, prostrauit. En ese mismo apartado de la especie de verbos activos que llevan un acusativo recoge, bajo un concepto, pequeños grupos de frases latinas relacionadas con ese concepto. Así, con la idea de «hacer el mal» recoge: Hic facinus suscipit, facit, efficit, admittit, committit. Y así otras ideas, como «imitar a los maestros», "robar», «conseguir», «extinguir» etc. De manera que este parte dedicada a la construcción se convierte en realidad en una copia verborum.

Y todo termina en la compositio. Tras los ejemplos de verbos activos de la primera especie, añade un ejemplo de composición en el que se utilizan y unen frases latinas similares a las que ha recogido anteriormente en los ejemplos:

Ex his sic contexe sermonem

Qui rem publicam gerere sapienter instituit, vt memoriam sui in animis hominum 
impressam relinquat, leges condit sanctissimas; perniciosas vero et statum reipublicae labefactantes euertit. Quibus institutis, viri boni officium et religionem accurate colant, et tenentes primas reipublicae sceleratorum nimiam potentiam extinguant... ${ }^{34}$.

(Con estas frases compón un discurso así

El que decide gobernar el estado con sabiduría para dejar impreso en las mentes de los hombres recuerdo de sí mismo, establece leyes muy buenas; deroga, por otro lado, las leyes perniciosas y que destruyen el estado. De acuerdo con estas instituciones, que sean los hombres buenos los que guarden cuidadosamente la administración y la religión y que, ocupando los primeros puestos del estado, reduzcan a la nada el excesivo poderío de los malos).

El Texe sermonem del final de los verbos activos de la tercera especie es, en 1580 , este:

Quam ob rem, si illi contenderint caeteris magistratibus laudem popularem praeripere et inuidia maleuorum ex/tincta ciuitati pacem et concordiam afferre, odio, amoreque vacui, dent palmam innocentibus viris, honores et praemia defferant literatis et fortibus, quorum consilio et armis salua diutius nitetur respublica. Si secus fecerint, non est dubium quin iniuria multis illata, hi ciuitati insanabile vulnus infligant et viri optimi abrogantes illis imperium, perniciem, exitium improbis hominibus comparent et suum laborem bonis subleuandis impertiant (fol. $84 \mathrm{r}-84 \mathrm{v}$ ).

(Por lo cual, si quieren arrebatar las alabanzas del pueblo a los demás magistrados, $y$, tras erradicar la maldad de los malos, traer la paz y la concordia a la ciudad, libres de odio y de favoritismo, den premio a los hombres inocentes, concedan honores y galardones a los sabios y fuertes, en cuyo consejo y armas se apoye salvo el estado durante largo tiempo. Si no lo hacen así, sin duda, injuriando a muchos, generarán una herida insanable a esta ciudad y los hombres buenos entregarán el mando, la desgracia y la muerte a los malos y dedicarán su esfuerzo a sublevar a los buenos) $)^{35}$.

Y así continúa con el resto de especies de verbos activos. Y con el resto de tipos de verbos.

${ }^{34}$ Esta última frase, en la edición de 1589, queda así: Quibus institutis viri boni suum munus accurate praestant, et tenentes primas reipublicae furorem improborum et arrogantiam comprimunt... (fol. 71v). Cambio fundamental es del presente de subjuntivo (colant y extinguant) en 1580 por el presente de indicativo (praestant y comprimunt) en 1589. Hay un cambio de actitud: el presente de subjuntivo era apremiante e incluso imperativo en 1580; el presente de indicativo sólo informa y declara en 1589. Suaviza, pues, su actitud. Es más, en 1580 añadía algo más que no está en 1589; es un largo párrafo en el que arremete contra los que perturban y revolucionan, todo, lo divino y lo humano; a esos el moderator reipublicae bueno debe reprimirlos con dureza.

${ }^{35}$ El de 1589, sin embargo es este: Si morem gesseris bonis et dederis palmam literatis, qui reipublicae maximum adiumentum important, magnam tibi gloriam et ornamentum paries et bonorum hominum beneuolentiam conciliabis. Si contra vulnus innocentibus inflexeris, quibus debemus omnes opem ferre, non est dubium quin ii tuis maculam nunquam delendam aspergant, manus et vim vehementius inferant, ut poenas debitas illis persoluas (fol. 75r). Mucho más breve, claro y racional. 
En el caso de los verbos pasivos, vuelve a insistir, desde un punto de vista programático, en lo que, como hemos venido viendo, es objetivo fundamental de su Gramática: enseñar usos elegantes de la lengua latina. Por eso dice que ha recogido frases con verbos en pasiva en aras de la elegancia y del ornato de la lengua latina:

Verbi passiui vsum institui tradere, cum, quia elegantia et copia non minus apparet in patiente quam in agente voce, tum quia modos loquendi non paucos et ad ornandam orationem aptissimos, in passiua usus recepit, in actiua non item. Vt tu es oculis captus, milites sunt desiderati, quamuis Cicero et Caesar dixerint, exercitu suo incolumi, vt ne vnum quidem desiderauerit. Hoc tamen raro incidit, illud vero frequentissime (p. 101). (He decidido tratar el uso de la pasiva, porque, si bien es cierto que la elegancia y la abundancia aparecen de la misma forma en la activa que en la pasiva, también lo es que no pocos giros latinos muy apropiados para el adorno del discurso se encuentran en la pasiva mejor que en la activa. Así, tu es oculis captus, milites sunt desiderati, aunque Cicerón y César dijeron exercitu suo incolumi, vt ne vnum quidem desiderauerit. Pero esto último es raro, mientras que el uso de la pasiva elegante es muy frecuente).

Conceder a la pasiva en determinados giros latinos más elegancia que a la activa responde a un hecho y a una doctrina: el hecho es que en latín la voz pasiva, sobre todo la bipartita, es decir la que sólo tiene sujeto y verbo en pasiva, es muy frecuente; la doctrina es que, cuando no se conoce o no se quiere expresar el agente de la acción, la forma más elegante de realizar la frase es la pasiva. Se dice en latín desiderati sunt multi («se perdieron muchos») en lugar de desideraverunt multos («echaron de menos a muchos»), que es mucho menos elegante.

A partir de aquí se extiende en multitud de clases y subclases de verbos, formas verbales, preposiciones, adverbios, con multitud de ejemplos y usos tomados de los autores latinos, sobre todo Cicerón, que convierten este libro tercero en una verdadera maraña muy difícil de aprender o asimilar. Es una lista de usos más que una Gramática al uso.

También en este punto hay diferencias entre 1580 y 1589 . Este libro tercero comienza así:

Praecepta communia. Verbum personale finitum antecedit nominatiuus vel eius loco oratio aut infinitum, ut Ego caeteris satisfacio, dolet mihi quod tu non stomacharis, vacare culpa magnum est solatium. Haec excipe et similia: lucescit, aduesparascit, aiunt, ferunt, in quibus facile intelligitur. Si duo nominatiui ad idem verbum spectent, hoc modo solent efferri: Iustitia, abstinentia, clementia tui Ciceronis reuiuiscunt, et Sic ego et Cicero valemus; Aliquando sic mens, consilium, ratio in senibus est

(Preceptos comunes.

Todo verbo personal finito lleva delante un nominativo o, en su lugar, una oración o un infinitivo; así Ego caeteris satisfazio, dolet mihi quod tu non stomacharis, vacare culpa magnum est solatium. Se exceptúan los siguientes y similares: lucescit, aduesparascit, aiunt, ferunt, en los cuales es fácilmente inteligible el nominativo.

Si se refieren a un mismo verbo dos nominativos, se suelen comportar así: Iustitia, abstinentia, clementia tui Ciceronis reuiuiscunt, et Sic ego et Cicero valemus; Aliquando sic mens, consilium, ratio in senibus est). 
En la letra de esta regla y en la cita de los ejemplos puesta en el margen coinciden las dos ediciones. Pero en la de 1589 se añade en el otro margen la traducción en español:

Verbum personale finitum antecedit nominatiuus vel eius loco oratio aut

3 fam.1 infinitum, ut Ego caeteris satisfazio, dolet Yo satisfago a los otros. Pesame que

2 ep. ad br. mihi quod tu non stomacharis, vacare no te enojes. No tener culpa es gran 3 fam.7 culpa magnum est solatium. Haec excipe et simmilia: lucescit, aduesparcit, aiunt, Va amaneciendo. Va haciendo tarde. ferunt, in quibus facile intelligitur.

Si duo nominatiui ad idem verbum

4 Att.5 spectent, hoc modo solent efferri: Iustitia, La justicia, la abstinencia, la clemen5 fm.14 abstinentia, clementia tui Ciceronis reui- cia de un cicerón tornan a vivir. Syllepsis uiscunt, et Sic ego et Cicero valemus; Yo y Cicerón estamos buenos. Senect. Aliquando sic mens, consilium, ratio in Zeuma senibus est.

Y así continúa en las demás reglas generales. Pero cuando comienza a hablar de cada tipo de verbo también en 1590 añadía la traducción en español, de manera que hay pequeñas variaciones entre una y otra edición. Así en el caso de la primera especie de verbos activos:

1580:

Rego, gero, administro, guberno remp. eius clauum teneo, gubernaculum teneo, gubernacula tracto. Eam consitituo, stabilio, sustento.

Ille remp. obsidet, labefactat, oppugnat, affligit, lacerat, opprimit, prodit, qui humana et diuina violauit, vexauit, perturbauit, euertit (fol. 73r)

Gouierno la republica.

Pongola en orden y en firmeza y susténtola.

Aquel cerca, maltrata, bate, aflige, destruye, oprime, y es traydor a la republica: El qual quebranto, perturbo, desryto las cosas humanas.

1589:

Rego, gero, administro, guberno remp. eius clauum teneo, gubernacula tracto. Ille remp. oppugnat, labefactat, lacerat, opprimit, prodit, qui humana et diuina violauit, vexauit, euertit (fol.73r)

Gouierno la republica.

Tengo el gobierno de ella.

Aquel persigue la republica, destruye maltrata, el cual quebranto, affligio, perturbo y arruino lo humano y lo diuino.

Al comienzo mismo de la clasificación de los verbos, en 1580 comenzaba con la división en verbo "sustantivo» y verbo «accidente», y seguía con la de «verbo personal» $\mathrm{y}$ «verbo impersonal». En 1589 comienza directamente con la clasificación en verbo personal e impersonal, saltando la división en «sustantivo» $\mathrm{y}$ «accidente». 
La diferencia fundamental entre una edición y otra está en que en la del 89 prescinde de una gran cantidad de frases latinas que estaban en 1580. Ya hemos dicho repetidas veces que las críticas que debió tener la primera edición por parte de los gramáticos racionalistas irían dirigidas sobre todo a la abundancia de ejemplos y frases latinas que incluía, cuya finalidad era la de enseñar a hablar latín; dado que los racionalistas sostenían que no se debía hablar latín, debieron criticar con dureza el texto de las Institutiones de Segura de 1580. El autor cede ante esas críticas y descarga sobremanera el nuevo texto de la reedición de ejemplos y frases.

Al final, como es normal en todas las Gramáticas de la época, incluye un capítulo dedicado a la Syntaxis figurata (fol. 174v):

\section{De oratione figurata}

Hactenus de constructione propria nunc de figurata dicamus.

Figura est nouata dicendi forma, quae cernitur in dictione, oratione, constructione.

Constructionis figuras septem persequar eclipsin, appositionem, syllepsin, zeugma, prolepsin, synedochen, antiptosin-

(Sobre la construcción figurada.

Hasta ahora hemos hablado de la construcción propia; ahora hablaremos de la figurada.

La figura es una forma de hablar renovada, que aparece a nivel de dicción, de oración y de construcción.

Trataré de siete figuras de construcción: elipsis, aposición, silepsis, zeugma, prolepsis, sinécdoque, antiptosis).

La adición al final de la Sintaxis de este apartado sobre Sintaxis figurada no parece ir más allá de un intento de incluir, dentro de la reforma, un capítulo que todo gramático sabía que era moderno. Es el deseo de aparecer como moderno. Pero no consigue exponer la doctrina sobre Sintaxis figurada que venía siendo moderna desde Linacro (1524). No lo consigue por varias razones. En primer lugar, porque principio básico de esta doctrina es que existen dos niveles de análisis de la frase; uno, mental o racional, en el que la frase tiene el esquema lógico que debe tener desde el punto de vista de la ratio y otro, de realización sintáctica (in dictione, oratione, constructione), en el que se pueden haber producido cambios (nouata dicendi forma); esos cambios se producen con la intervención de las figuras de construcción y lo que resulta es sintaxis figurada. Segura no habla para nada de análisis. En segundo lugar, porque los gramáticos racionales agrupan esas figuras en cuatro tipos: figuras por adición (pleonasmo), por sustracción (elipsis y sus variantes), por cambio de orden (hipérbaton) y por cambio de función (enálage); en el texto anterior Segura anuncia que va a tratar de siete figuras, las tradicionales, y no habla para nada de un esquema cuatripartito, que era esencial en los gramáticos que distinguían racionalmente entre sintaxis propria y sintaxis figurata. Intenta, pues, en su afán de reforma ser moderno, pero ciertamente no lo consigue.

\section{PROSODIA Y MÉTRICA}

De la misma forma que el Arte de Nebrija termina con un libro dedicado a la Prosodia y Métrica, también Segura termina con ellas. 
La novedad es de nuevo el recurso a frases o versos tomados de los poetas clásicos, sobre todo Virgilio. Así los siguientes:

Omnis diphtongus est longa, vt audio; breuis est in praeuro, praeeo, et aliis. Sententia est: Omnis syllaba scripta diphtongo est longa sic:

Audierat tyrias olim quae verteret arces Aen. I (20)

$A u$ est longa quia diphtongus. Breuis est in praeuro, praeeo, praeacutus

Stipitibus duris agitur sudibusne praeustis Aen. 7 (524)

Nec tota tamen ille prior praeeunte catina Aen. 5 (186)

(Todo diptongo es una sílaba larga, como sucede en audio; es, sin embargo, breve en el caso de praeuro, praeeo, y otras palabras semejantes. La regla es: Toda sílaba escrita con diptongo es larga como sucede en

Audierat tyrias olim quae verteret arces Aen. I (20)

$A u$ es larga porque es diptongo. Pero es breve en el caso de praeuro, praeeo, praeacutus Stipitibus duris agitur sudibusne praeustis Aen. 7 (524)

Nec tota tamen ille prior praeeunte catina Aen. $5(186))$

En 1589 mantiene los ejemplos. Ello es lógico, porque en el caso de la Prosodia y la Métrica los ejemplos no se traen para que el alumno aprenda frases, sino como muestra de la regla prosódica o métrica.

\section{CONCLUSIÓN}

En la segunda mitad del siglo XVI aparecen una buena cantidad de Institutiones de Gramática, sobre todo en las Universidades de Salamanca, Alcalá y Valencia, las cuales, frente a las Introductiones de Nebrija, que era la Gramática oficial y que se había convertido en un manual largo y difícil para los alumnos, trataban de imponerse apareciendo como una Gramática más breve y racional que la de Antonio. Intentan, pues, reformar a Antonio, no suplantarle, lo cual era imposible. Es el caso de las Institutiones de Segura en Alcalá, editada por primera vez en 1580 y reeditada en 1586 y 1589. La primera edición de Segura, de 1580, se presenta como breve y racional, pero también como instrumento para enseñar a hablar latín, para lo cual incorpora al texto gramatical una cantidad considerable de frases latinas, en buena medida ciceronianas. Debió recibir críticas Segura por esto último. Y por ello, en la reedición de 1589, aparte de otros cambios, suprime una buena cantidad de las frases y ejemplos latinos. Ha cedido algo ante la presión de los gramáticos racionalistas que sostenían que no se debía hablar latín.

\section{REFERENCIAS BIBLIOGRÁFICAS}

Del Estal Fuentes, E. (1975): Francisco Sánchez de las Brozas. Minerva (1562), Universidad de Salamanca, Salamanca.

García Calvo, A. (1958): «Funciones del lenguaje y modalidades de la frase», Estudios Clásicos 4 (24): 329-350.

Hernández Miguel, L. A. (1996): «La Gramática Latina en Alcalá de Henares en el siglo XVI», Humanistica Lovaniensia 45: 319-347. 
Maestre Maestre, J. Ma . (1989): «Barbatos Perotos: los tópicos del prólogo dedicatoria de la Minerva», Actas del Simposio Internacional IV Centenario de la Minerva del Brocense (1587-1987), Cáceres, pp. 203-232.

Maestre Maestre, J. Ma . (1998-90): «El Brocense contra Nebrija; nuevos datos sobre el prólogo dedicatoria de la Minerva", Alor Novísimo 16-18: 22-32.

MARINer Bigorra, S. (1957): «Estructura de la categoría verbal 'modo’ en latín clásico», Emerita 25: 449-485.

Rubio, L. (1968): «Los modos verbales», Emerita 35: 77-96.

SÁnCHEZ SAlOR, E. (1999): «La Gramática de Nebrija reformada», en A. Ma. Martins Melo (coord.), Actas do I Congresso Internacional. Humanismo novilatino e pedagogia (Gramáticas, Criaçōes maiores e teatro), Universidade Católica Portuguesa, Braga, pp. 99-129.

SÁNCHEZ SALOR, E. (2002): De las «elegancias» a las «causas» de la lengua: retórica y gramática del humanismo, IEH-CSIC, Alcañiz-Madrid.

SÁnCheZ SALOR, E. (2003): «QQué Arte de Gramática enseñar en el siglo XVI? El caso de Valencia», en F. Grau i Codina (ed.), La Universitat de València i l'humanisme. "Studia Humanitatis" i renovació cultural a la Europa i al nou món, Universidad de Valencia, Valencia, pp. 193-220.

SÁNCHEZ SALOR, E. (2005): «Comentarios a la Gramática latina de Nebrija. Su significado y contenido", en J. COSTAS RodríGUEZ (coord.), Ad amicam amicissime scripta. Homenaje a María José López de Ayala y Genovés, UNED, Madrid, vol. II, pp. 169-178.

SÁNCHEZ SALOR, E. (2006): «La Gramática del maestro Martínez Lusitano. Entre Nebrija y el Brocense», Revista portuguesa de Humanidades 10 (1-2): 53-80.

SÁnChez SAlor, E. (2008): Las ediciones del Arte de Gramática de Nebrija (1481-1700). Historia bibliográfica, Editora Regional de Extremadura, Mérida. 
